Ana Clara Viola ${ }^{1}$

Vera Lúcia Edais Pepe ${ }^{1}$

Miriam Ventura ${ }^{2}$

\title{
LONGO CAMINHO A PERCORRER NA VOLTA PARA A SOCIEDADE: O MINISTÉRIO PÚBLICO E A DESINSTITUCIONALIZAÇÃO EM SAÚDE MENTAL
}

The long way back to society: The Brazilian Public Prosecution Service and the deinstitutionalization of mental health

${ }^{1}$ Fundação Oswaldo Cruz. Escola Nacional de Saúde Pública Sérgio Arouca. Rio de Janeiro/RJ, Brasil.

${ }^{2}$ Universidade Federal do Rio de Janeiro. Instituto de Saúde Coletiva. Rio de Janeiro/RJ, Brasil. Correspondência: Ana Clara Viola. E-mail: soaresviola@gmail.com

Recebido: 10/04/2018. Revisado: 07/02/2019. Aprovado: 09/04/2019. 


\section{RESUMO}

A busca pela garantia dos direitos civis e sociais como direitos indissociáveis foi crescente a partir dos anos 1970, influenciando a reorganização dos modelos assistenciais à saúde diante do reconhecimento de novos sujeitos de direitos. Um dos aspectos mais evidentes desse cenário no Brasil foi a visibilidade da Reforma Psiquiátrica como parte estruturante da Reforma Sanitária Brasileira que acompanhou o movimento dos direitos humanos. Este estudo tem como elemento central contribuir com a qualificação do processo de monitoramento da política de saúde mental pelo Ministério Público Estadual a partir da observância dos principais aspectos debatidos academicamente em relação ao processo de desinstitucionalização de pessoas. Trata-se de uma pesquisa qualitativa constituída de busca sistemática de evidências nas literaturas técnica (normativas, portarias, leis, resoluções) e científica, a partir de dados eletrônicos da Biblioteca Virtual em Saúde e que utilizou como descritores: "desinstitucionalização" $A N D$ "saúde mental" $O R$ "hospitais psiquiátricos". Destaca-se que o Ministério Público é uma instituição permanente e essencial do Estado de Direito, incumbido por obrigação constitucional de atuar na defesa dos interesses sociais, da ordem jurídica e do regime democrático.

\section{Palavras-Chave}

Desinstitucionalização; Ministério Público; Monitoramento; Saúde Coletiva; Saúde Mental.

\section{ABSTRACT}

The guarantee civil and social rights as inseparable rights has been increasingly sought for since the 1970s and has influenced the reorganization of health care models in face of the recognition of new subjects of right. In Brazil, one of the most evident aspects of this scenario was the visibility of the Psychiatric Reform as a structuring part of the Brazilian Health Reform that treaded along the human rights movement. This study aims to contribute to the qualification of the mental health policy monitoring process by the State Prosecutor's Office, based on the compliance with the main points of academic debates on process of deinstitutionalization of people. This is a qualitative research study consisting of a systematic search for evidence in technical (norms, ordinances, laws, resolutions) and scientific literature, based on electronic data from the Biblioteca Virtual em Saúde and using the descriptors: "deinstitutionalization" AND "mental health" OR "psychiatric hospitals". It should be noted that the Brazilian Public Prosecution Service is a permanent and essential institution of the rule of law, entrusted with the constitutional obligation of acting in defense of social interests, the legal system and the democratic regime.

\section{Keywords}

Deinstitutionalization; Public Attorney; Monitoring; Public Health; Mental Health. 


\section{Introdução}

As reivindicações por direitos civis e sociais de grupos específicos como direitos indissociáveis, e as propostas de reformas sociais e sanitárias em todo o mundo robusteceram-se nos anos 1970. Fundamentadas nos direitos humanos e em forte movimento internacional, exigiram uma redefinição dos modelos assistenciais à saúde. Nessa conjuntura, iniciou-se a busca por um novo lugar social dos "loucos", onde pudessem ser reconhecidos enquanto sujeitos de direitos.

No Brasil, essas reivindicações ganharam visibilidade com o movimento dos trabalhadores em saúde mental (1987) e dos usuários e familiares, que denunciavam as violações de direitos humanos perpetradas pelas instituições e as práticas de saúde no tratamento dos transtornos mentais, bem como a ineficiência do modelo assistencial manicomial vigente ${ }^{1}$. O desafio de acolher as singularidades humanas e de romper com a trajetória histórica de intolerância para com os ditos "loucos", bem como outras classes excluídas e estigmatizadas, se impôs na agenda sanitária e de direitos humanos. A Reforma Psiquiátrica ganhou força, em compasso com a Reforma Sanitária, dando início a um processo longo e complexo de conjugação da saúde como um direito de cidadania e de justiça social, bem como de reconhecimento dos "loucos" como sujeitos de direitos próprios, e não como pacientes-objetos de intervenções médicas encarceradoras.

Amarante $^{2}$ descreve a Reforma Psiquiátrica brasileira como um processo social complexo, que exige a

articulação de várias dimensões que são simultâneas e inter-relacionadas, que envolvem movimentos, atores, conflitos e uma tal transcendência do objeto de conhecimento que nenhum método cognitivo ou teoria podem captar e compreender em sua complexidade e totalidade ${ }^{3}$.

O autor propõe quatro dimensões para análise do processo de reforma psiquiátrica: epistemológica ou teórico-conceitual, técnico-assistencial, jurídico-política e sociocultural.

Este estudo adotou a dimensão jurídico-política, em que se destacam dois marcos importantes dessa reforma no Brasil: a Portaria da Secretaria Nacional de Assistência à Saúde do Ministério da Saúde (SNAS/MS) n. 189/1991 e a Portaria

\footnotetext{
${ }^{1}$ FERRO, Luís Felipe. Trabalho territorial em hospitais psiquiatricos: construindo no presente um futuro sem manicomios. Psicol. cienc. prof., Brasília-DF, v. 29, n. 4, p. 752-767, 2009. Disponível em: http://www. scielo.br/pdf/pcp/v29n4/v29n4a08.pdf. https://doi.org/10.1590/S1414-98932009000400008.

${ }^{2}$ AMARANTE, Paulo. A (clínica) e a reforma psiquiátrica. In: AMARANTE, Paulo (Coord.). Arquivos de Saúde Mental e Atenção Psicossocial. Rio de Janeiro: Nau, 2003. p. 45-65.

${ }^{3}$ Id. Ibid., p. 49.

${ }^{4}$ MINISTÉRIO DA SAÚDE - MS. Portaria SNAS/MS n. 189, de 19 de novembro de 1991. Aprova a inclusão de Grupos e Procedimentos da Tabela do SIH-SUS, na área de Saúde Mental (Hospitais Psiquiátricos). Disponível em: http://www.maringa.pr.gov.br/cisam/portaria189.pdf. Acesso em: 30 jan. 2020.
} 
SNAS/MS n. 224/1992 5 . Na primeira, o Ministério da Saúde alterou o financiamento da saúde mental e ampliou os serviços substitutivos. Na segunda, regulamentou os serviços e incorporou as diretrizes e os princípios do Sistema Único de Saúde (SUS), estabelecidos pela Constituição Federal de $1988^{6}$ (CF/88) e regulamentados pela Lei Federal n. 8.080/19907. Um aspecto central da nova regulamentação foi a ênfase na desospitalização das pessoas portadoras de transtornos mentais e na qualificação da assistência a elas.

A importância da desinstitucionalização revela-se de forma contundente na Lei Federal n. $10.216 / 2001^{8}$, que estabelece critérios e procedimentos obrigatórios relativos à internação psiquiátrica como medida excepcional. Prevê, ainda, a obrigatória intervenção do Judiciário e do Ministério Público nos casos de internação involuntária e compulsória, estabelecendo procedimentos próprios de proteção à pessoa com transtorno mental, como dito, agora sujeitos de direitos subjetivos próprios.

O propósito legal pretende romper com a trajetória histórica de encarceramento e intolerância social. A Lei Federal n. 10.216/2001 estabeleceu a política de saúde mental e as responsabilidades do Estado, da sociedade e dos familiares no cuidado das pessoas com transtornos mentais. Assim, consolidou, no plano jurídico-político, direitos subjetivos próprios das pessoas com transtornos mentais que estabelecem a organização da atenção à saúde mental em redes, e não mais de forma asilar. Componentes hospitalares e extra-hospitalares são elementos essenciais da rede para a reintrodução dessas pessoas na comunidade e para o desenvolvimento de sua autonomia em liberdade. No ano de 2011, o Ministério da Saúde expediu a Portaria do Gabinete do Ministério (GM/MS) n. 3.088/20119, republicada em 21 de maio de 2013, que instituiu a Rede de Atenção Psicossocial (RAPS) para pessoas com sofrimento ou transtorno mental e com necessidades decorrentes do uso de crack, álcool e outras drogas, no âmbito do SUS.

Os arcabouços jurídico-político e técnico-assistencial, construídos durante três décadas, consolidam-se na Política Nacional de Saúde Mental (PNSM), que

\footnotetext{
${ }^{5}$ MINISTÉRIO DA SAÚDE - MS. Portaria SNAS/MS n. 224, de 29 de janeiro de 1992. Disponível em: http://www.saude.mg.gov.br/images/documentos/Portaria_224.pdf. Acesso em: 30 jan. 2020.

${ }^{6}$ BRASIL. Constituição da República Federativa do Brasil de 1988. Disponível em: http://www.planalto.gov. br/ccivil_03/constituicao/constituicaocompilado.htm. Acesso em: 30 jan. 2020.

${ }^{7}$ BRASIL. Lei n. 8.080, de 19 de setembro de 1990. Dispõe sobre as condições para a promoção, proteção e recuperação da saúde, a organização e o funcionamento dos serviços correspondentes e dá outras providências. Disponível em: http://www.planalto.gov.br/ccivil_03/leis/L8080.htm. Acesso em: 30 jan. 2020. ${ }^{8}$ BRASIL. Lei n.10.216, de 06 de abril de 2001. Dispõe sobre a proteção e os direitos das pessoas portadoras de transtornos mentais e redireciona o modelo assistencial em saúde mental. Disponível em: http://www.planalto.gov.br/ccivil_03/leis/leis_2001/I10216.htm. Acesso em: 30 jan. 2020.

${ }^{9}$ No ano de 2017, a Portaria MS/GM n. 3.088/2011 foi revogada pela Portaria de Consolidação n. 03/2017, que reuniu as principais normas sobre as redes do Sistema Único de Saúde (SUS). (MINISTÉRIO DA SAÚDE. Portaria de Consolidação n. 03, de 28 de setembro de 2017. Consolidação das normas sobre as redes do Sistema Único de Saúde. Disponível em: http://bvsms.saude.gov.br/bvs/saudelegis/gm/2017/ prc0003_03_10_2017.html. Acesso em: 30 mar. 2020.
} 
expressamente preconiza a reabilitação psicossocial por meio da desinstitucionalização de usuários longamente hospitalizados e o cuidado integral à pessoa com transtornos mentais (Lei n. 10.216/2001). Ainda que a PNSM tenha atingido resultados expressivos, muitas ainda são as dificuldades para sua efetiva implementação, de forma que garanta a continuidade do cuidado fora de ambiente hospitalar. Portanto, os direitos de cidadania desse segmento da população revelam-se ainda hoje um desafio.

Entre as instituições de Justiça, o Ministério Público (MP) tem importância central na promoção e defesa de direitos à vista de sua dupla tarefa constitucional: é responsável pela proteção e tutela individual de direitos de segmentos vulneráveis (como as pessoas com transtornos mentais); e pelo acompanhamento das políticas públicas e ações necessárias à promoção e garantia desses direitos no âmbito da tutela coletiva ${ }^{10}$.

Compreendendo a desinstitucionalização como um processo social complexo de desconstrução e construção de cidadania, e não meramente de desospitalização e reorganização de serviços ${ }^{11}$, o MP tem tido uma atuação fundamental. Estudos sobre o tema apontam a importância da atuação do MP na garantia de direitos desse segmento e seu potencial como interlocutor e mediador efetivo junto aos gestores de saúde no processo de implementação das políticas de saúde ${ }^{12}$.

No âmbito da discussão das ações e da articulação entre saúde pública e direito, mostram-se relevantes estudos que busquem identificar as possibilidades de conexões conceituais e metodológicas entre esses dois campos de saberes e práticas, bem como produções que contribuam para a interlocução entre as instituições de Justiça e de saúde na efetivação dos direitos.

Buscando contribuir com a atuação do Ministério Público, no âmbito da política de saúde mental, este estudo traz os principais aspectos debatidos academicamente no processo de desinstitucionalização de pessoas com transtornos mentais longamente institucionalizadas, e avança no sentido de identificar elementos, a partir desses estudos especializados, que ajudem na qualificação do acompanhamento desse processo pelo Ministério Público.

\footnotetext{
${ }^{10}$ MINISTÉRIO PÚBLICO DO ESTADO DO RIO DE JANEIRO - MPERJ. Ministério Público e tutela à saúde mental: a proteção de pessoas portadoras de transtornos psiquiátricos e de usuários de álcool e drogas. 2. ed. Rio de Janeiro, ago. 2011. Disponível em http://msm.mp.rj.gov.br/wp-content/uploads/2013/01/cartilha_ saude_mental_versao_final.pdf. Acesso em: 03 fev. 2014.

${ }^{11}$ AMARANTE, Paulo. O homem e a serpente: outras histórias para a loucura e a psiquiatria. Rio de Janeiro: Ed. Fiocruz, 1996.

${ }^{12}$ ASENSI, Felipe Dutra. Indo além da Judicialização: o Ministério Público e a saúde no Brasil. Rio de Janeiro: Escola de Direitos do Rio de Janeiro da Fundação Getúlio Vargas, Centro de Justiça e Sociedade, 2010. 206p. Disponível em: https://bibliotecadigital.fgv.br/dspace/bitstream/handle/10438/10313/ Indo\%20al\%c3\%a9m\%20da\%20Judicializa\%c3\%a7\%c3\%a3o\%20-\%200\%20Minist\%c3\%a9rio\%20 P\%c3\%bablico\%20e\%20a\%20sa\%c3\%bade\%20no\%20Brasil.pdf?sequence=1\&isAllowed=y.
} 


\section{Metodologia}

Entende-se por “indivíduo longamente institucionalizado" aquele que permaneceu ou permanece por período de tempo igual ou maior que um ano em uma instituição com características de instituições totais ${ }^{13}$. Tais instituições são baseadas em relações de poder e controle, por parte da equipe dirigente, sobre necessidades humanas dos internos; além disso, constituem local de tratamento e cura onde práticas coercitivas e o isolamento da sociedade tornam-se princípios do tratamento ${ }^{14,15}$.

Para o estudo, foi realizada pesquisa qualitativa constituída de busca sistemática de evidências nas literaturas científica e técnica, adotando-se como critério de inclusão estudos das principais estratégias, experiências e outros elementos importantes para o acompanhamento do processo de desinstitucionalização pelo Ministério Público.

A busca de referencial técnico incluiu documentos - relatórios, manuais, recomendações técnicas e normativas (portarias, leis, resoluções) - de publicação oficial no período de 2001 a 2014 e com acesso público. Optou-se pela busca a partir de 2001 a fim de capturar as normativas posteriores à Lei n. 10.216/2001, dado que houve um incremento significante de normativas para a área de saúde mental após sua promulgação. Foram incluídos nove documentos, sendo sete normativas do Ministério da Saúde, dois relatórios do Sistema Único de Saúde (SUS), da Secretaria Estadual de Saúde do Rio de Janeiro, um da Secretaria Municipal de Saúde de Itaboraí (RJ) e três ações civis públicas do Ministério Público. Foi analisado, também, o relatório final da IV Conferência Estadual de Saúde Mental do Rio de Janeiro.

A busca da literatura foi realizada em bases de dados eletrônicas da Biblioteca Virtual em Saúde (BVS). Selecionaram-se, a partir de Descritores em Ciências da Saúde ${ }^{16}$ (DeCS), as palavras-chave de interesse e chaves de busca: "desinstitucionalização" $A N D$ "saúde mental" $O R$ "hospitais psiquiátricos”. Foram incluídos, após leitura dos resumos e aplicação dos critérios de inclusão e exclusão, 42 textos, dentre eles, uma tese, cinco dissertações, duas monografias e 34 artigos.

A presente pesquisa não envolveu direta ou indiretamente seres humanos, eliminando a necessidade de submissão do projeto ao Comitê de Ética em Pesquisa, de acordo com o preconizado pela Resolução do Conselho Nacional da Saúde (CNS) n. 466/2012.

\footnotetext{
${ }^{13}$ PEPE, Vera Lúcia Edais. Internações e reinternações psiquiátricas no Estado do Rio de Janeiro. 2002. Tese (Doutorado) - Faculdade de Medicina da Universidade de São Paulo, São Paulo, 2002.

${ }^{14}$ LUCENA, Marcela Adriana da Silva; BEZERRA, Adriana Falangola Benjamin. Reflexões sobre a gestão de processos de desinstitucionalização. Ciênc. saúde coletiva, Rio de Janeiro, v. 17, n. 9, p. 2447-2456, set. 2012. Disponivel em: http://www.scielo.br/pdf/csc/v17n9/a25v17n9.pdf. https://doi.org/10.1590/ S1413-81232012000900025.

${ }^{15}$ GOFFMAN, Erving. Manicômios, prisões e conventos. São Paulo: Ed. Perspectiva, 1961.

${ }^{16}$ BIBLIOTECA VIRTUAL EM SAÚDE PÚBLICA. Descritores em Ciências da Saúde. Disponível em: http://decs.bvs.br/.
} 


\section{O Ministério Público na saúde}

A CF/88, em seu artigo 127, definiu o MP como "instituição permanente, essencial à função jurisdicional do Estado, incumbindo-lhe a defesa da ordem jurídica, do regime democrático e dos interesses sociais e individuais indisponíveis”. Especificando suas funções institucionais, o artigo 129 estabelece que o MP é uma instituição dinâmica, autônoma e permanente no sistema judicial brasileiro, sem submissão hierárquica ou funcional aos três poderes (Executivo, Judiciário e Legislativo).

A autonomia institucional fundamenta-se na essencialidade de sua atuação em prol da sociedade, na promoção e garantia de direitos em face do próprio Estado. Constitui-se, portanto, ator político relevante na implementação de políticas públicas no cenário contemporâneo pós-reforma constitucional ${ }^{17}$. A respeito de ser uma instituição dinâmica, Sadek ${ }^{18}$ destaca que se trata de uma característica que possibilita o controle de sua própria agenda, priorizando tarefas e estabelecendo uma política institucional.

O Ministério Público brasileiro é composto pelo Ministério Público da União (MPU) - Ministério Público Federal (MPF), Ministérios Públicos do Distrito Federal e Territórios (MPDFT), Ministério Público do Trabalho (MPT) e Ministério Público Militar (MPM) - e pelos Ministérios Públicos Estaduais (MPE). É comum a atuação conjunta dessas instituições ao tratarem de direitos de responsabilidade solidária dos entes federativos, como a saúde. A instituição possui instrumentos formais para atuação nas esferas extrajudicial e judicial, que são: o inquérito civil (IC); a recomendação; as audiências públicas; a ação civil pública (ACP); e o termo de ajustamento de conduta (TAC) - estes dois últimos são seus principais meios de atuação ${ }^{19}$.

O IC é uma investigação prévia realizada pelos membros do MP, tanto da União quanto dos Estados, a fim de apurar se houve irregularidade e de identificar o responsável, por meio da coleta de elementos de convencimentos para a propositura da ação civil pública. A recomendação é um meio de o Poder Judiciário alertar sobre a necessidade de resolver uma situação irregular ou que possa levar a alguma irregularidade; assim, ele recomenda a órgãos e entidades a adoção de medidas para a adequação da prestação dos serviços públicos e para o respeito de interesses e direitos dos cidadãos. As audiências públicas são espaços democráticos de participação dos cidadãos a fim de colaborarem para o MP no exercício de suas finalidades e na tomada de decisão. Já a ACP é ação judicial que o MP pode propor ao Judiciário para a garantia de um direito difuso e/ou coletivo que se encontra violada. O TAC

\footnotetext{
${ }^{17}$ SADEK, Maria Teresa. A construção de um novo Ministério Público resolutivo. Palestra apresentada na Semana do Ministério Público de Minas Gerais, em 08/9/2008. Disponível em: https://aplicacao.mpmg. mp.br/xmlui/handle/123456789/135. Acesso em: 11 abr. 2014.

${ }^{18}$ Id. Ibid.

${ }^{19}$ ASENSI, Felipe Dutra. op. cit.
} 
é um instrumento que firma um acordo entre o MP e o gestor municipal, estadual ou federal, com obrigações previamente estabelecidas entre as partes que devem ser cumpridas pelos gestores responsáveis por alguma irregularidade ou dano, visando a corrigir uma situação débil ${ }^{20}$.

Além dos instrumentos formais de atuação acima citados, o MP pode, ainda, atuar através de expedição de ofícios e realização de reuniões, audiências públicas e seminários com o objetivo de discutir temas relevantes para a atuação do parquet na área da saúde. Vale dizer que essas formas de atuação valorizam o diálogo e a participação dos atores envolvidos para a tomada de decisão.

A partir da emergência de tais instrumentos de atuação - principalmente a ação civil pública - e da normatização dos direitos coletivos, pode-se dizer que o MP, com suas atribuições de guardião e fiscal dos direitos da sociedade, tem sido importante agente impulsionador da defesa dos direitos coletivos pela via judicial $^{21}$ e extrajudicial.

O MP tem diversos órgãos de execução nos quais atuam procuradores e promotores de justiça. Os promotores de justiça atuam na tutela tanto individual quanto na coletiva. A tutela individual busca solucionar conflitos e violações de direitos de indivíduos, com efeitos restritos à pessoa representada. Na tutela coletiva, os promotores de justiça atuam de forma a intervir em situações e interesses coletivos, por exemplo, utilizando-se de investigações relacionadas à política e a prestações de serviços estatais e atos de improbidade administrativa, entre outros, com o propósito de zelar pelo efetivo funcionamento das políticas e ações garantidoras dos direitos da sociedade.

\section{A desinstitucionalização como processo de produção de saúde e garantia de direitos de liberdade}

A análise da literatura e documental permitiu sistematizar elementos constitutivos dos diferentes processos de desinstitucionalização, adotando como referencial as dimensões da Reforma Psiquiátrica elaboradas por Amarante ${ }^{22}$. Importante salientar que essas dimensões são simultâneas e inter-relacionadas e, por isso, os elementos selecionados por este estudo possuem características de mais de uma dimensão, dependendo de suas especificidades e do alcance das ações a serem desenvolvidas.

\footnotetext{
${ }^{20}$ ASENSI, Felipe Dutra. op. cit.

${ }^{21}$ ARANTES, Rogério Bastos. Direito e política: o Ministério Público e a defesa dos direitos coletivos. RBCS: revista brasileira de ciências sociais, v. 14, n. 39, p. 83-102, fev. 1999. Disponível em: http://www.scielo. br/pdf/rbcsoc/v14n39/1723.pdf. Acesso em; 11 abr. 2014.

${ }^{22}$ AMARANTE, Paulo. A (clínica) e a reforma psiquiátrica, cit., p. 45-65.
} 
A dimensão teórico-conceitual ou epistemológica refere-se ao campo de produção de saberes e de conhecimento, perpassando desde os fundamentos da ciência enquanto produtora de verdades até os conceitos próprios da psiquiatria. Visa a "entender e capturar a lógica com a qual os saberes foram construídos e, assim (se possível), não reproduzí-los mais" ${ }^{\text {”2 }}$. Busca-se questionar a racionalidade científica moderna a fim de abrir espaço para um novo olhar sobre a experiência da loucura, bem como a produção de novos conceitos sobre um novo objeto, este não mais sendo a doença, e sim o indivíduo em seu sofrimento, existência e relação com as condições de vida ${ }^{2425}$.

A revisão da literatura e documental possibilitou reunir os resultados referentes a esta dimensão em dois grupos, a saber: (i) espaço de troca de saberes e experiências e (ii) intersetorialidade, conforme o Quadro 1. No primeiro grupo, os elementos destacados são indispensáveis para que os profissionais de saúde trabalhem em sintonia com a política de saúde mental ${ }^{26,27}$. Ressaltam a importância de incorporar estratégias de educação permanente e capacitação que busquem transformar as práticas profissionais adequando-as aos novos conhecimentos.

Nesse sentido, é relevante no acompanhamento identificar/estimular essas ações, buscando a construção contínua de uma clínica antimanicomial que vise não mais à cura da pessoa, mas à maximização de sua autonomia e à devolução de seus direitos de cidadã, tendo o território como espaço gerador de possibilidade para produção de vida, o que se chama de politização da clínica.

Os elementos relacionados à intersetorialidade destacam a necessidade de ações que garantam para além do setor saúde, tendo em vista que o indivíduo passa a ser visto como cidadão portador de direitos, o que requer da política de saúde pensar além da clínica, buscando na intersetorialidade condições para isso. As práticas intersetoriais são, portanto, indispensáveis ao processo de desinstitucionalização, compreendendo a Reforma Psiquiátrica como processo social complexo.

\footnotetext{
${ }^{23}$ AMARANTE, Paulo. A (clínica) e a reforma psiquiátrica, cit., p. 45-65.

${ }^{24}$ YASUI, Silvio. Rupturas e encontros: desafios da reforma psiquiátrica brasileira. 2009. Tese (Mestrado em Saúde Pública) - Escola Nacional de Saúde Pública Sérgio Arouca - FIOCRUZ, Rio de Janeiro. 2009. Disponivel em: http://bases.bireme.br/cgi-bin/wxislind.exe/iah/online/?lsisScript=iah/iah.xis\&src=google \&base=LILACS\&lang=p\&nextAction=Ink\&exprSearch=490878\&indexSearch=ID. Acesso em: 11 abr. 2014.

${ }^{25}$ AMARANTE, Paulo. A (clínica) e a reforma psiquiátrica, cit., p. 45-65.

${ }^{26}$ BARROS, Sônia; SALLES, Mariana. Gestão da atenção à saúde mental no Sistema Único de Saúde. Rev. esc. enferm. USP, São Paulo, v. 45, n. 2, p. 1780-1785, dez. 2011. http://www.scielo.br/pdf/reeusp/ v45nspe2/25.pdf. https://doi.org/10.1590/S0080-62342011000800025.

${ }^{27}$ BEZERRA, Cíntia Guedes; DIMENSTEIN, Magda. Acompanhamento terapêutico na proposta de altaassistida implementada em hospital psiquiátrico: relato de uma experiência. Psicol. clin., Rio de Janeiro, v. 21, n. 1, p. 15-32, 2009. http://www.scielo.br/pdf/pc/v21n1/v21n1a02.pdf. https://doi.org/10.1590/ S0103-56652009000100002.
} 
Quadro 1. Elementos relacionados à dimensão epistemológica, de interesse para a qualificação do acompanhamento da desinstitucionalização pelo Ministério Público

\begin{tabular}{|c|c|}
\hline Elementos da dimensão epistemológica & Referência \\
\hline \multicolumn{2}{|c|}{ Elemento 1: Estratégias de educação permanente e capacitação voltadas para profissionais de saúde } \\
\hline $\begin{array}{l}\text { Aspecto 1: Existência de cursos de formação, orientação, } \\
\text { conscientização e capacitação para os trabalhadores que } \\
\text { atuam na rede de saúde mental, incluindo hospitais gerais, } \\
\text { ambulatórios, serviços de urgência e emergência, serviços } \\
\text { substitutivos, hospitais psiquiátricos e atenção básica. } \\
\text { Exemplos de temas relevantes para cursos: (i) sofrimento } \\
\text { mental grave; (ii) dependentes de substâncias psicoativas; } \\
\text { (iii) pessoas vivendo com HIV/AIDS; (iv) intervenção em crise; } \\
\text { (v) atuação nos Núcleos de Geração de Trabalho e Renda; } \\
\text { (vi) atenção básica e saúde mental; (vii) matriciamento; } \\
\text { (viii) uso racional de psicotrópicos; (ix) saúde mental infanto- } \\
\text { juvenil. Existência de relatórios de planejamento dos cursos e } \\
\text { avaliação por todos os participantes }\end{array}$ & $\begin{array}{l}\text { • Portaria GM/MS } \\
\text { n. } 3.088 / 2011 \\
\text {-IV Conferência Estadual de } \\
\text { Saúde Mental - Intersetorial }\end{array}$ \\
\hline $\begin{array}{l}\text { Aspecto 2: Incentivo a participação dos profissionais que } \\
\text { atuam no município nas estratégias de educação permanente } \\
\text { e capacitação desenvolvidas pelas Secretarias de Saúde e } \\
\text { Ministério da Saúde com a temática da saúde mental }\end{array}$ & - Literatura \\
\hline \multicolumn{2}{|l|}{ Elemento 2: Intersetorialidade } \\
\hline $\begin{array}{l}\text { Aspecto 3: Mecanismos de fortalecimento da articulação do } \\
\text { setor de saúde com diversos setores governamentais e não } \\
\text { governamentais, tais como educação, cultura, trabalho e } \\
\text { religião, possibilitando a participação dos indivíduos portadores } \\
\text { de transtornos mentais nos mais diversos equipamentos } \\
\text { disponíveis no território. Existência de documentos que } \\
\text { comprovem as pactuações intersetoriais realizadas, bem como } \\
\text { as atividades planejadas e desenvolvidas }\end{array}$ & $\begin{array}{l}\text { - Lei Federal n. 10.216/2001 } \\
\text { - Literatura } \\
\text { - IV Conferência Estadual de } \\
\text { Saúde Mental - Intersetorial } \\
\text { - Portaria GM/MS } \\
\text { n. } 3.088 / 2011\end{array}$ \\
\hline $\begin{array}{l}\text { Aspecto 4: Articulação da Secretaria de Saúde Municipal } \\
\text { com os setores de educação, inclusive universidades, para a } \\
\text { promoção de educação continuada aos profissionais de saúde } \\
\text { que atuam na saúde mental, bem como para a inserção dos } \\
\text { indivíduos portadores de transtornos mentais em escolas e } \\
\text { cursos profissionalizantes }\end{array}$ & - Literatura \\
\hline $\begin{array}{l}\text { Aspecto 5: Investimento do município em projetos de geração } \\
\text { de renda que envolvam os serviços de saúde mental }\end{array}$ & $\begin{array}{l}\text {-IV Conferência Estadual de } \\
\text { Saúde Mental - Intersetorial }\end{array}$ \\
\hline $\begin{array}{l}\text { Aspecto 6: Realização, pelos serviços de saúde mental em } \\
\text { parceria, por exemplo, com Defensoria Pública, Cartório e } \\
\text { Assistencial Social, de ações voltadas à emissão de carteira } \\
\text { de identidade, CPF, carteira de trabalho e cadastro para os } \\
\text { usuários receberem os benefícios a que têm direito }\end{array}$ & $\begin{array}{l}\text { - Lei Federal n. } 10.708 / 2003^{28} \\
\text { - Portaria GM/MS } \\
\text { n. } 3.088 / 2011\end{array}$ \\
\hline
\end{tabular}

Fonte: Elaboração própria.

\footnotetext{
${ }^{28}$ BRASIL. Lei n. 10.708, de 31 de julho de 2003. Institui o auxílio-reabilitação psicossocial para pacientes acometidos de transtornos mentais egressos de internações. Disponível em: http://www.planalto.gov.br/ ccivil_03/Leis/2003/L10.708.htm. Acesso em: 13 fev. 2020.
} 
A dimensão jurídico-política diz respeito à necessidade de uma transformação social e das normativas para que haja uma ruptura com noções estabelecidas pela psiquiatria relacionando loucura à periculosidade, irracionalidade e incapacidade. Em termos de cidadania e direitos humanos, a ruptura com essas noções permite reconhecer os "loucos" como sujeitos de direitos subjetivos próprios e comuns a todos, como o da liberdade ${ }^{29,30}$.

Nesse sentido, foram selecionados 23 aspectos de interesse para o monitoramento dessa dimensão, que envolve desde a gestão das secretarias de saúde no processo de desinstitucionalização até a regulação e o financiamento dessas ações (Quadro 2). Os aspectos dispostos nos diferentes elementos expressam a importância de se garantirem, por meio de normas e pactuações políticas entre os entes federativos, instrumentos de gestão que vão desde de auditorias e avaliações das condições da atenção até estratégias de regulação da rede de atenção e financiamento das ações.

Destaca-se a Lei n. 10.216/2001, base da PNSM, e que redireciona o modelo assistencial em saúde mental, prevendo a organização da atenção à saúde mental em redes a fim de incorporar não apenas os componentes hospitalares, mas também extra-hospitalares essenciais à reintrodução do sujeito na comunidade, sendo de responsabilidade dos estados e municípios a garantia de assistência territorializada.

Ainda que esses serviços extra-hospitalares tenham demonstrado ser efetivos para substituir a internação, bem como na inserção social do indivíduo e para o desenvolvimento de sua autonomia ${ }^{31}$, estudos recentes têm demonstrado algumas barreiras a serem superadas. Alguns autores ressaltaram o potencial de institucionalização dos Centros de Atenção Psicossocial (CAPS), na medida em que reproduzem as características do modelo manicomial e não rompem com as práticas e os saberes da psiquiatria tradicional, preservando a tutela, o controle e a hierarquia entre profissionais de saúde e usuários ${ }^{32,33,34}$.

\footnotetext{
${ }^{29}$ AMARANTE, Paulo. A (clínica) e a reforma psiquiátrica, cit., p. 45-65.

${ }^{30}$ YASUI, Silvio. op. cit.

${ }^{31}$ NASI, Cíntia; SCHNEIDER, Jacó Fernando. O Centro de Atenção Psicossocial no cotidiano dos seus usuários. Rev. esc. enferm., USP, São Paulo, v. 45, n. 5, p. 1157-1163, out. 2011. Disponível em: http://www. scielo.br/pdf/reeusp/v45n5/v45n5a18.pdf. Acesso em: 08 jan. 2014. https://doi.org/10.1590/S008062342011000500018.

${ }^{32}$ PANDE, Mariana Nogueira Rangel; AMARANTE, Paulo Duarte de Carvalho. Desafios para os Centros de Atenção Psicossocial como serviços substitutivos: a nova cronicidade em questão. Ciênc. saúde coletiva, Rio de Janeiro, v. 16, n. 4, abr. 2011. Disponível em: http://www.scielo.br/pdf/reeusp/v45n5/v45n5a18. pdf. Acesso em: 08 jan. 2014. https://doi.org/10.1590/S0080-62342011000500018.

${ }^{33}$ FIGUEIREDO, Vanda Valle de; RODRIGUES, Maria Margarida Pereira. Atuação do psicólogo nos CAPS do Estado do Espírito Santo. Psicologia em Estudo, Maringá, v. 9, n. 2, ago. 2004. Disponível em: https://www. researchgate.net/publication/240768092_Atuacao_do_psicologo_nos_CAPS_do_Estado_do_Espirito_ Santo Acesso em: 08 jan. 2014. https://doi.org/10.1590/S1413-73722004000200004.

${ }^{34}$ LIBERATO, Mariana Tavares Cavalcanti; DIMENSTEIN, Magda. Arte, loucura e cidade: a invenção de novos possíveis. Psicol. Soc., Belo Horizonte, v. 25, n. 2, p. 272-281, 2013. Disponível em: http://www.scielo.br/ pdf/psoc/v25n2/04.pdf.
} 
No que tange aos elementos relacionados à gestão da atenção em saúde mental, a criação de departamentos, coordenações, assessorias, comissões, áreas técnicas e grupos de trabalho nas secretarias de Saúde e no Ministério da Saúde, desde que de acordo com a PNSM, mostrou-se pertinente para a garantia da continuidade das ações, segundo estudos que relataram experiências de desinstitucionalização ${ }^{35,36}$. No entanto, a questão da alta rotatividade dos profissionais das secretarias de saúde, em razão de interesses políticos, e o envolvimento dos gestores com a questão da saúde mental são aspectos relevantes para a sustentabilidade das políticas locais.

Quadro 2. Elementos relacionados à dimensão jurídico-política, de interesse para a qualificação do acompanhamento da desinstitucionalização pelo Ministério Público

\begin{tabular}{|l|l|}
\hline Elementos da dimensão jurídico-política & \multicolumn{1}{|c|}{ Referência } \\
\hline Elemento 1: Gestão da secretaria de saúde no processo de desinstitucionalização \\
\hline $\begin{array}{l}\text { Aspecto 1: Existência de Plano Municipal e Estadual de Saúde Mental } \\
\text { e Plano Estadual e/ou Municipal de Apoio à Desinstitucionalização } \\
\text { condizentes com a proposta da Reforma Psiquiátrica }\end{array}$ & - Literatura \\
\hline $\begin{array}{l}\text { Aspecto 2: Habilitação do município no Programa de Volta Para } \\
\text { Casa, dentre outras bolsas e benefícios do MS e das secretarias } \\
\text { estaduais e municipais de Saúde cujo alvo sejam os indivíduos } \\
\text { portadores de transtornos mentais. Controle da relação dos } \\
\text { beneficiados, do responsável pelo controle do dinheiro e da relação } \\
\text { dos indivíduos que aguardam autorização para o recebimento dos } \\
\text { benefícios com a justificativa para ainda não receberem }\end{array}$ & $\begin{array}{c}\text { • Portaria GM/MS } \\
\text { n. 132/2012 }\end{array}$ \\
\hline $\begin{array}{l}\text { Aspecto 3: Avaliações (de estrutura física e contábeis) realizadas } \\
\text { pelo Executivo da Saúde em hospitais psiquiátricos do município. } \\
\text { Existência de relatórios das avaliações }\end{array}$ & $\bullet$ \\
\hline $\begin{array}{l}\text { Aspecto 4: Estratégias desenvolvidas pelo município para } \\
\text { a redução de leitos hospitalares, inclusive conveniados e } \\
\text { contratados. Existência de documentos que formalizem } \\
\text { a composição do grupo responsável pelas atividades; o } \\
\text { planejamento das ações, com indicação dos recursos } \\
\text { necessários; as metas, indicando as atingidas e as não atingidas; } \\
\text { as estratégias para o alcance das metas; e os mecanismos de } \\
\text { monitoramento e avaliação das estratégias utilizadas }\end{array}$ & \\
\hline
\end{tabular}

Continua

${ }^{35}$ GUITTON, Anna Paula Aparecida de Lima. Trajetórias do processo de desinstitucionalização psiquiátrica noestado do Rio de Janeiro: uma análise a partir das estratégias políticas para o hospital psiquiátrico. 2010. 189 f. Dissertação (Mestrado em Saúde Pública) - Escola Nacional de Saúde Pública Sérgio Arouca, Rio de Janeiro, 2010. Disponível em: https://www.arca.fiocruz.br/handle/icict/23508.

${ }^{36}$ GULJOR, Ana Paula Freitas. O fechamento do hospital psiquiátrico e o processo de desinstitucionalização no município de Paracambi: um estudo de caso. 2013. 356f. Tese (Doutorado em Saúde Pública) - Escola Nacional de Saúde Pública Sergio Arouca, Rio de Janeiro, 2013.

${ }^{37}$ MINISTÉRIO DA SAÚDE - MS. Portaria GM/MS n. 132, de 26 de janeiro de 2012. Institui incentivo financeiro de custeio para desenvolvimento do componente Reabilitação Psicossocial da Rede de Atenção Psicossocial do Sistema Único de Saúde (SUS). Disponível em: http://bvsms.saude.gov.br/bvs/saudelegis/ gm/2012/prt0132_26_01_2012.html. Acesso em: 13 fev. 2020. 
Continuação

\begin{tabular}{|c|c|}
\hline Elementos da dimensão jurídico-política & Referência \\
\hline \multicolumn{2}{|c|}{ Elemento 1: Gestão da secretaria de saúde no processo de desinstitucionalização } \\
\hline $\begin{array}{l}\text { Aspecto 5: Diagnóstico situacional dos internos de hospitais } \\
\text { psiquiátricos com realização de Censo Clínico e Psicossocial, } \\
\text { incluindo o mapeamento dos não munícipes }\end{array}$ & $\begin{array}{l}- \text { ACP } \\
\text { - Literatura }\end{array}$ \\
\hline $\begin{array}{l}\text { Aspecto 6: Auditorias realizadas pelo estado e pela União, seja } \\
\text { pelo Tribunal de Contas seja pelo próprio Executivo da Saúde, } \\
\text { sobre avaliação operacional e contábil da situação dos hospitais } \\
\text { psiquiátricos localizados no município e que se encontram em } \\
\text { situação irregular }\end{array}$ & $\cdot \mathrm{ACP}$ \\
\hline $\begin{array}{l}\text { Aspecto 7: Existência de assessorias, grupos de apoio técnico } \\
\text { e interinstitucional, comissões (tripartite e/ou bipartite) } \\
\text { dentre outros grupos em âmbito federal, estadual e municipal } \\
\text { para atuação no processo de desinstitucionalização dos } \\
\text { pacientes longamente institucionalizados no município. } \\
\text { Existência de documentos que formalizem a composição de } \\
\text { tais grupos; o planejamento das ações, com indicação dos } \\
\text { recursos necessários; as metas, indicando as atingidas e as } \\
\text { não atingidas; as estratégias para o alcance das metas; e os } \\
\text { mecanismos de monitoramento e avaliação das estratégias de } \\
\text { desinstitucionalização utilizadas }\end{array}$ & $\begin{array}{l}- \text { ACP } \\
\text { - Literatura }\end{array}$ \\
\hline $\begin{array}{l}\text { Aspecto 8: Existência de Colegiado de Gestão no âmbito das } \\
\text { unidades (especialmente hospitais) de saúde mental que inclua } \\
\text { gestores municipais, estaduais e funcionários das unidades a fim } \\
\text { de impulsionar as ações de reorientar a assistência nas unidades. } \\
\text { Existência de documentos que formalizem a composição de tais } \\
\text { grupos e as atividades pactuadas e desenvolvidas por eles }\end{array}$ & - Literatura \\
\hline $\begin{array}{l}\text { Aspecto 9: Atividades planejadas e realizadas de monitoramento e } \\
\text { avaliação da qualidade dos serviços de saúde mental por meio de } \\
\text { indicadores de efetividade e resolutividade da atenção para subsidiar } \\
\text { o planejamento e acompanhamento da política de saúde mental } \\
\text { local. Existência de documentos que formalizem a composição do } \\
\text { grupo responsável e as atividades pactuadas e desenvolvidas por eles }\end{array}$ & $\begin{array}{l}\text { - Portaria GM/MS } \\
\text { n. } 3.088 / 2011\end{array}$ \\
\hline $\begin{array}{l}\text { Aspecto 10: Apoio jurídico aos usuários e trabalhadores de saúde } \\
\text { mental nas ações de desinstitucionalização }\end{array}$ & $\begin{array}{l}\text { - IV Conferência Estadual de } \\
\text { Saúde Mental - Intersetorial }\end{array}$ \\
\hline $\begin{array}{l}\text { Aspecto 11: Existência de conselhos gestores nas Unidades } \\
\text { de Saúde Mental que contem com a participação dos usuários } \\
\text { e familiares. Existência de documentos que formalizem a } \\
\text { composição de tais grupos e relatórios de reunião }\end{array}$ & $\begin{array}{l}\text { - IV Conferência Estadual de } \\
\text { Saúde Mental - Intersetorial }\end{array}$ \\
\hline $\begin{array}{l}\text { Aspecto 12: Estratégias de articulação entre saúde mental, } \\
\text { Judiciário, Ministério Público e Defensoria Pública para } \\
\text { promoção de discussão qualificada sobre o processo de } \\
\text { desinstitucionalização no município }\end{array}$ & $\begin{array}{l}\text { - IV Conferência Estadual de } \\
\text { Saúde Mental - Intersetorial }\end{array}$ \\
\hline $\begin{array}{l}\text { Aspecto 13: Concursos públicos planejados e realizados para } \\
\text { a contratação de estatutários para a rede de saúde mental } \\
\text { do município, contemplando toda a equipe preconizada nas } \\
\text { normativas e objetivando substituir os profissionais contratados }\end{array}$ & $\begin{array}{l}\text { - IV Conferência Estadual de } \\
\text { Saúde Mental - Intersetorial }\end{array}$ \\
\hline
\end{tabular}


Continuação

\begin{tabular}{|c|c|}
\hline Elementos da dimensão jurídico-política & Referência \\
\hline \multicolumn{2}{|l|}{ Elemento 2: Regulação } \\
\hline $\begin{array}{l}\text { Aspecto 14: Existência de central de regulação integrada } \\
\text { pelos três entes federados. Existência de documentos de } \\
\text { monitoramento e avaliação das solicitações de internação } \\
\text { (por tipo de internação: compulsória, voluntária e involuntária) } \\
\text { e consultas em saúde mental, e de protocolos de regulação } \\
\text { pactuados e utilizados }\end{array}$ & $\begin{array}{c}\text { • Portaria GM/MS } \\
\text { n. 3.088/2011 }\end{array}$ \\
\hline $\begin{array}{l}\text { Aspecto 15: Existência de Rede de Atenção Psicossocial (RAPS) } \\
\text { pactuada, com desenho dos fluxos assistenciais definidos, } \\
\text { protocolos assistenciais e mapeamento dos dispositivos da rede. } \\
\text { Existência de documentos que formalizem a composição da RAPS }\end{array}$ & $\begin{array}{l}\text { • Portaria GM/MS } \\
\text { n. } 3.088 / 2011\end{array}$ \\
\hline $\begin{array}{l}\text { Aspecto 16: Cadastro atualizado dos serviços de saúde da } \\
\text { RAPS e dos profissionais no sistema de Cadastro Nacional de } \\
\text { Estabelecimento de Saúde (CNES) e dos usuários no sistema do } \\
\text { Cartão Nacional de Saúde (CNS) }\end{array}$ & $\begin{array}{l}\text { - IV Conferência Estadual de } \\
\text { Saúde Mental - Intersetorial }\end{array}$ \\
\hline $\begin{array}{l}\text { Aspecto 17: Existência de Plano Diretor de Regionalização (PDR); } \\
\text { Plano Diretor de Investimentos (PDI) e Programação Pactuada } \\
\text { Integrada (PPI), com definição das redes, das ações, dos } \\
\text { serviços de saúde mental e dos recursos financeiros destinados, } \\
\text { elaborada respeitando as pactuações da Comissão Intergestores } \\
\text { Bipartite e revisada caso haja alterações no fluxo assistencial, na } \\
\text { oferta de serviços e nos limites financeiros, entre outros }\end{array}$ & $\begin{array}{l}\text { - IV Conferência Estadual de } \\
\text { Saúde Mental - Intersetorial }\end{array}$ \\
\hline $\begin{array}{l}\text { Aspecto 18: Cadastro do município para recebimento de } \\
\text { medicamentos do Componente Especializado da Assistência } \\
\text { Farmacêutica fornecidos pelo estado. Existência de listagem } \\
\text { atualizada de medicamentos ofertados pela rede do SUS aos } \\
\text { usuários de serviços de saúde mental }\end{array}$ & $\begin{array}{l}\text { - IV Conferência Estadual de } \\
\text { Saúde Mental - Intersetorial }\end{array}$ \\
\hline $\begin{array}{l}\text { Aspecto 19: Existência de mecanismos de distribuição dos } \\
\text { medicamentos aos usuários da rede de saúde mental e } \\
\text { mecanismos de monitoramento da dispensação }\end{array}$ & $\begin{array}{l}\text { - IV Conferência Estadual de } \\
\text { Saúde Mental - Intersetorial }\end{array}$ \\
\hline \multicolumn{2}{|l|}{ Elemento 3: Financiamento } \\
\hline $\begin{array}{l}\text { Aspecto 20: Existência de mecanismos de controle da reorientação } \\
\text { dos recursos financeiros provenientes dos leitos hospitalares } \\
\text { descredenciados. Existência de documentos que comprovem o } \\
\text { quantitativo de leitos descredenciados, seus respectivos valores } \\
\text { financeiros e destinação destes na rede de saúde mental }\end{array}$ & $\begin{array}{l}\text { - IV Conferência Estadual de } \\
\text { Saúde Mental - Intersetorial }\end{array}$ \\
\hline $\begin{array}{l}\text { Aspecto 21: Pactuações de transferência dos recursos } \\
\text { financeiros para o Fundo Municipal com a finalidade de } \\
\text { custear o encerramento das atividades ou o saneamento das } \\
\text { irregularidades dos hospitais psiquiátricos que necessitarem. } \\
\text { Existência de resoluções que aprovem a transferência financeira } \\
\text { e de documentos de prestação de conta que comprovem a } \\
\text { regularidade do repasse financeiro e sua destinação }\end{array}$ & - ACP e Literatura \\
\hline $\begin{array}{l}\text { Aspecto 22: Relatórios de prestação de contas dos recursos } \\
\text { financeiros destinados à saúde mental e repassados ao Fundo } \\
\text { Municipal de Saúde }\end{array}$ & $\begin{array}{l}\text { - IV Conferência Estadual de } \\
\text { Saúde Mental - Intersetorial }\end{array}$ \\
\hline
\end{tabular}

Fonte: Elaboração própria. 
A dimensão sociocultural, definida como aquela que objetiva uma mudança da concepção da loucura no imaginário social, tem o propósito de observar ações que efetivamente levem a pessoa com transtorno mental ao convívio social, sem discriminação e/ou estigma.

Nessa dimensão, os estudos identificados apontam a importância de refletir sobre a receptividade e a solidariedade da comunidade em relação a esse segmento durante seu processo de desinstitucionalização. Por essa razão, a participação social é o elemento-chave da dimensão sociocultural (Quadro 3).

As atividades desenvolvidas pelos serviços substitutivos entre os familiares, usuários e comunidade em geral, como oficinas, idas ao cinema, teatro, passeios pelas ruas da comunidade, entre outros, são exemplos de atividades culturais que visam à construção de subjetividades e de reinserção das pessoas com transtornos mentais na comunidade ${ }^{38,39}$.

Quadro 3. Elementos relacionados à dimensão sociocultural, de interesse para a qualificação do acompanhamento da desinstitucionalização pelo Ministério Público

\begin{tabular}{|l|l|}
\hline Elementos da dimensão sociocultural & \multicolumn{1}{|c|}{ Referência } \\
\hline Elemento 1: Participação social & $\bullet$ Portaria GM/MS \\
Aspecto 1: Atividades de saúde mental desenvolvidas pelos \\
dispositivos de saúde (inclusive atenção básica) no território, com o \\
envolvimento da sociedade e dos usuários dos serviços. Existência \\
de documentos de pactuação, planejamento e avaliação das \\
atividades territoriais pactuadas e realizadas, bem como a frequência \\
dos repasses financeiros destinados a tais ações. Identificar se \\
há parcerias/convênios com outros setores (Assistência Social, \\
$\begin{array}{l}\text { Secretarias de Trabalho, Cultura e Educação, Defensoria Pública, } \\
\text { Ministério Público, entre outras) para a realização dessas atividades }\end{array}$ & \\
\hline $\begin{array}{l}\text { Aspecto 2: Mecanismos utilizados pela gestão municipal do SUS } \\
\text { e pelos dispositivos de saúde mental de inclusão de sindicatos, } \\
\text { familiares, comunidade e Conselho Municipal de Saúde no } \\
\text { processo de desinstitucionalização }\end{array}$ & $\bullet$ \\
\hline $\begin{array}{l}\text { Aspecto 3: Mecanismos de monitoramento e avaliação utilizados pelos } \\
\text { dispositivos de saúde mental sobre a participação de cada indivíduo } \\
\text { nas atividades coletivas em âmbito institucional e comunitário, bem } \\
\text { como desenvolvimento de vínculos sociais pelos indivíduos a fim de } \\
\text { avaliar o alcance dos objetivos de reintegração social }\end{array}$ & \\
\hline $\begin{array}{l}\text { Aspecto 4: Existência de espaços de convivência comunitária } \\
\text { apoiados pela Secretaria Municipal de Saúde }\end{array}$ & \\
\hline
\end{tabular}

Fonte: Elaboração própria.

\footnotetext{
${ }^{38}$ ANAYA, Felisa Cançado. Problematização do conceito de serviços substitutivo em saúde mental: a contribuição do CERSAM de Belo Horizonte-MG. 2014. 155f. Dissertação (Mestrado em Saúde Pública) Escola Nacional de Saúde Pública, Fundação Oswaldo Cruz, Rio de Janeiro, 2004.

${ }^{39}$ BORSA, Juliane Callegaro; EIDELWEIN, Karen. Conhecendo a realidade da saúde mental no Rio Grande do Sul. Psico, PUC/RS, Porto Alegre, v. 36, n. 2, p. 159-165, 2005. https://www.researchgate.net/ publication/260592314_Conhecendo_a_Realidade_da_Saude_Mental_no_Rio_Grande_do_Sul.
} 
Os conceitos que constituem o saber psiquiátrico e sua prática estão diretamente relacionados com o modelo assistencial que se estabelece. É nesse sentido que Amarante ${ }^{40}$ discute a dimensão técnico-assistencial. Os principais conceitos da psiquiatria tradicional, tais como doença mental, alienação, isolamento terapêutico, tratamento moral, cura, degeneração, saúde mental e normalidade/anormalidade, corroboram um modelo assistencial que isola, vigia, tutela, disciplina e pune.

Segundo Yasui:

A dimensão técnico-assistencial: em um constante movimento entre a prática e a teoria, ou seja, no movimento de uma práxis, propõe-se a construção de uma nova organização de serviços, articulando uma rede de espaços de sociabilidade, de produção de subjetividades, de geração de renda, de apoio social, de moradia, enfim, de produção de vida ${ }^{41}$.

Destacaram-se quatro elementos nessa dimensão, que evidenciaram 32 aspectos de monitoramento: Rede de Atenção Psicossocial (RAPS); oficinas terapêuticas; projeto terapêutico; e alta hospitalar e acompanhamento terapêutico (Quadro 4). Trata-se de dispositivos que integram o novo modelo assistencial psiquiátrico e que são necessários à boa prática. A RAPS, composta por serviços hospitalares e não hospitalares, surge como proposta de desconstrução do modelo manicomial. É um serviço que, em articulação com os recursos da comunidade, possibilita a reabilitação psicossocial do indivíduo em processo de desinstitucionalização. O papel dos agentes comunitários de saúde é essencial nessa articulação, pois são, em geral, moradores da comunidade que conhecem os recursos e as famílias, o que facilita o desenvolvimento de ações técnico-políticas que mobilizem diversos espaços da comunidade no processo de produção da saúde.

Já as oficinas terapêuticas constituem dispositivos que favorecem a inserção do indivíduo na sociedade com o estímulo ao aprendizado, à criatividade e à socialização. Possibilitam, portando, a inserção no mercado de trabalho e o acesso a comunicação.

Por fim, o projeto terapêutico no processo de desinstitucionalização pode ser entendido como missão institucional do serviço em seu território de abrangência e como relação contratual estabelecida entre profissional da saúde e usuário, sendo um projeto individualizado ou singular ${ }^{42}$.

Produzir o Projeto Terapêutico Singular (PTS) requer escuta ampliada e coleta de informação sobre a vida do sujeito a fim de traçar estratégias terapêuticas e de acompanhamento do usuário em conformidade com suas necessidades, enquanto o Projeto

\footnotetext{
${ }^{40}$ AMARANTE, Paulo. A (clínica) e a reforma psiquiátrica, cit., p. 45-65.

${ }^{41}$ YASUI, Silvio. op. cit., p. 98.

${ }^{42}$ DANTAS, Alexandre César. Serviços residenciais terapêuticos em saúde mental: potencialidades e limitações no município de Camaragibe/PE. Recife: [s.n.], 2010. 61p.
} 
Terapêutico Institucional (PTI) é um instrumento que norteia as atividades desenvolvidas pelos profissionais de saúde e seu cumprimento, viabilizando, a partir de espaços coletivos, o questionamento das atividades desenvolvidas e a proposição de mudanças ${ }^{43}$.

Quadro 4. Elementos relacionados à dimensão técnico-assistencial, de interesse para a qualificação do acompanhamento da desinstitucionalização pelo Ministério Público

\begin{tabular}{|c|c|}
\hline Elementos da dimensão técnico assistencial & Referência \\
\hline \multicolumn{2}{|l|}{ Elemento 1: Rede de Atenção Psicossocial (RAPS) } \\
\hline $\begin{array}{l}\text { Aspecto 1: Mecanismos para cadastramento dos indivíduos nos serviços de } \\
\text { saúde mental e existência de guias para orientação dos fluxos assistenciais }\end{array}$ & $\begin{array}{l}\text { - IV Conferência } \\
\text { Estadual de Saúde } \\
\text { Mental - Intersetorial }\end{array}$ \\
\hline $\begin{array}{l}\text { Aspecto 2: Mapeamento dos dispositivos que compõem a rede de saúde } \\
\text { mental do município, com quantitativo e modalidade assistencial. Existência } \\
\text { de relatórios de avaliação da suficiência dos dispositivos de saúde mental } \\
\text { de acordo com a demanda do município, inclusive considerando internos de } \\
\text { hospitais psiquiátricos em outros municípios. Existência de planejamento } \\
\text { para a expansão dos serviços de saúde mental }\end{array}$ & $\begin{array}{l}\text { - Portaria GM/MS } \\
\text { n. } 3.088 / 2011 \\
\text { - Portaria } \\
\text { n. } 336 / 2002^{44}\end{array}$ \\
\hline $\begin{array}{l}\text { Aspecto 3: Avaliação da conformidade dos recursos humanos existentes } \\
\text { nos dispositivos de saúde mental segundo quantitativo e categoria } \\
\text { profissional preconizados em portarias específicas }\end{array}$ & $\begin{array}{c}\text { - Portaria GM/MS } \\
\text { n. } 3.090 / 2011^{45} \\
\text { - Portaria GM/MS } \\
\text { n. } 336 / 2002\end{array}$ \\
\hline $\begin{array}{l}\text { Aspecto 4: Avaliação quantitativa e qualitativa das atividades } \\
\text { desempenhadas pelos CAPS conforme portaria específica, especialmente } \\
\text { em relação a: (i) organização da demanda e da rede de cuidados em saúde } \\
\text { mental; (ii) regulação da porta de entrada da rede assistencial no âmbito do } \\
\text { seu território; (iii) coordenação das atividades de supervisão de unidades } \\
\text { hospitalares psiquiátricas; (iv) matriciamento nas equipes de atenção } \\
\text { básica, serviços e programas de saúde mental; (v) realização e atualização } \\
\text { do cadastramento dos pacientes que utilizam medicamentos essenciais } \\
\text { para a área de saúde mental; (vi) atendimento individual e em grupo; (vii) } \\
\text { oficinas terapêuticas; (viii) visitas domiciliares; e (ix) atendimento à família } \\
\text { e atividades comunitárias. Identificar se há parcerias/convênios com outros } \\
\text { setores (Assistência Social, secretarias de Trabalho, Cultura e Educação, } \\
\text { dentre outras) para a realização dessas atividades }\end{array}$ & $\begin{array}{l}\text { - Portaria GM/MS } \\
\text { n. } 336 / 2002\end{array}$ \\
\hline
\end{tabular}

\footnotetext{
${ }^{43}$ LIMA, Alyne Vieira. A gestão do processo de trabalho e a clínica: um estudo de caso no Hospital Colônia de Barreiros-PE. 2010. 74f. Dissertação (Mestrado em Saúde pública) - Centro de Pesquisas Aggeu Magalhães, Fundação Oswaldo Cruz, Recife, 2010. Disponivel em: https://www.arca.fiocruz.br/handle/icict/13688.

${ }^{44}$ MINISTÉRIO DA SAÚDE - MS. Portaria MS n. 336, de 19 de fevereiro de 2002. Disponível em: http://bvsms. saude.gov.br/bvs/saudelegis/gm/2002/prt0336_19_02_2002.html. Acesso em: 13 fev. 2020.

${ }^{45}$ MINISTÉRIO DA SAÚDE - MS. Portaria GM/MS n. 3.090, de 23 de dezembro de 2011. Altera a Portaria n. 106/GM/MS, de 11 de fevereiro de 2000, e dispõe, no âmbito da Rede de Atenção Psicossocial, sobre o repasse de recursos de incentivo de custeio e custeio mensal para implantação e/ou implementação e funcionamento dos Serviços Residenciais Terapêuticos (SRT). Disponível em: http://bvsms.saude.gov.br/ bvs/saudelegis/gm/2011/prt3090_23_12_2011_rep.html. Acesso em: 13 fev. 2020.
} 
Continuação

\begin{tabular}{|c|c|}
\hline Elementos da dimensão técnico assistencial & Referência \\
\hline \multicolumn{2}{|l|}{ Elemento 1: Rede de Atenção Psicossocial (RAPS) } \\
\hline $\begin{array}{l}\text { Aspecto 5: Avaliação quantitativa e qualitativa das atividades desempenhadas } \\
\text { nos Serviços de Residência Terapêutica (SRT) especialmente em relação } \\
\text { a: (i) auxiliar os moradores no uso do dinheiro; (ii) estimular as relações } \\
\text { interpessoais; (iii) estimular a responsabilização e apropriação dos moradores } \\
\text { pela casa coletiva que habitam; (iv) estimular a comunicação e a resolução de } \\
\text { problemas que enfrentam no dia a dia; dentre outras ações que contribuam para } \\
\text { o desenvolvimento da autonomia dos moradores e a reinserção social. Identificar } \\
\text { se há parcerias/convênios com outros setores (Assistência Social, secretarias de } \\
\text { Trabalho, Cultura e Educação, dentre outras) para a realização dessas atividades }\end{array}$ & - Literatura \\
\hline $\begin{array}{l}\text { Aspecto 6: Vinculação dos SRT a um serviço/equipe de saúde mental de } \\
\text { referência, preferencialmente um CAPS, para a integralidade do cuidado dos } \\
\text { moradores, em consonância com os respectivos projetos terapêuticos individuais }\end{array}$ & $\begin{array}{c}\text { - Portaria GM/MS } \\
\text { n. } 3.090 / 2011\end{array}$ \\
\hline $\begin{array}{l}\text { Aspecto 7: Existência de serviços substitutivos (SRT, CAPS) localizados } \\
\text { em estrutura física de unidade hospitalar. Em caso positivo, existência de } \\
\text { acesso independente e recursos humanos próprios }\end{array}$ & $\begin{array}{c}\text { - Portaria GM/MS } \\
\text { n. } 336 / 2002\end{array}$ \\
\hline $\begin{array}{l}\text { Aspecto 8: Existência, no âmbito dos serviços substitutivos (SRT, CAPS), } \\
\text { de áreas de acesso restrito aos profissionais de saúde, de modo a } \\
\text { restringir erroneamente o acesso dos usuários dos serviços }\end{array}$ & - Literatura \\
\hline $\begin{array}{l}\text { Aspecto 9: Existência de planejamento das atividades desenvolvidas pelos } \\
\text { serviços de saúde com indicação de atividades programadas, objetivos, } \\
\text { horários e frequência de realização, bem como relatórios de monitoramento } \\
\text { e avaliação das atividades. Participação de todos os atores envolvidos no } \\
\text { processo de planejamento, monitoramento e avaliação das atividades }\end{array}$ & - Literatura \\
\hline $\begin{array}{l}\text { Aspecto 10: Existência de agenda de fiscalização dos serviços de saúde mental } \\
\text { pela Secretaria Municipal de Saúde, pelos conselhos Estadual, Municipal e } \\
\text { Distritais de Saúde. Existência de relatórios de fiscalizações já realizadas }\end{array}$ & $\begin{array}{c}\text { - Portaria GM/MS } \\
\text { n. } 3.090 / 2011\end{array}$ \\
\hline $\begin{array}{l}\text { Aspecto 11: Estratégias de articulação entre atenção básica e } \\
\text { dispositivos de saúde mental, por exemplo, reuniões periódicas para } \\
\text { compartilhamento dos projetos terapêuticos dos usuários em seus } \\
\text { territórios. Existência de documentos de planejamento e avaliação das } \\
\text { ações, contendo a frequência das ações desenvolvidas, os profissionais } \\
\text { participantes e a percepção deles sobre o resultado das estratégias }\end{array}$ & $\begin{array}{l}\text {-IV Conferência } \\
\text { Estadual de Saúde } \\
\text { Mental - Intersetoria }\end{array}$ \\
\hline $\begin{array}{l}\text { Aspecto 12: Existência de Núcleo de Apoio à Saúde da Familia (NASF) e equipes } \\
\text { de matriciamento em saúde mental no município. Quantitativo de equipes } \\
\text { e profissionais que o compõem, e ações desenvolvidas em conjunto com os } \\
\text { demais dispositivos da rede de saúde mental, tais como: realização de grupos, } \\
\text { visitas domiciliares, oficinas, atendimentos em conjunto e discussão de casos }{ }^{46}\end{array}$ & $\begin{array}{l}\text { - ACP } \\
\text { - Literatura } \\
\text { - IV Conferência } \\
\text { Estadual de Saúde } \\
\text { Mental - Intersetoria }\end{array}$ \\
\hline
\end{tabular}

Continua

\footnotetext{
${ }^{46}$ A Portaria GM/MS n. 2.979/2019 instituiu o Programa Previne Brasil, que estabelece novo modelo de financiamento de custeio da atenção primária à saúde no âmbito do SUS. As mudanças propostas vigentes a partir de 2020 alteram a organização da área e afetam o NASF. O NASF foi identificado no contexto normativo vigente à época do estudo como elemento importante para o monitoramento. (MINISTÉRIO DA SAÚDE. Portaria n. 2.979, de 12 de novembro de 2019. Institui o Programa Previne Brasil, que estabelece novo modelo de financiamento de custeio da Atenção Primária à Saúde no âmbito do Sistema Único de Saúde, por meio da alteração da Portaria de Consolidação n. 6/GM/MS, de 28 de setembro de 2017. Disponível em: http://www. in.gov.br/en/web/dou/-/portaria-n-2.979-de-12-de-novembro-de-2019-227652180. Acesso em: 30 mar. 2020.
} 
Continuação

\begin{tabular}{|c|c|}
\hline Elementos da dimensão técnico assistencial & Referência \\
\hline \multicolumn{2}{|l|}{ Elemento 1: Rede de Atenção Psicossocial (RAPS) } \\
\hline $\begin{array}{l}\text { Aspecto 13: Existência de estratégias de acolhimento e atendimento à } \\
\text { crise no âmbito da atenção básica e em hospitais gerais, como protocolos } \\
\text { e escuta qualificada }\end{array}$ & $\begin{array}{l}\text { - IV Conferência } \\
\text { Estadual de Saúde } \\
\text { Mental - Intersetorial }\end{array}$ \\
\hline $\begin{array}{l}\text { Aspecto 14: Existência de equipes multidisciplinares, interdisciplinares ou } \\
\text { transdisciplinares e intersetoriais volantes e consultórios de rua para o } \\
\text { atendimento a pessoas com transtornos mentais, em parceria com a Rede de } \\
\text { Atenção Básica, a Rede de Saúde Mental e a Assistência Social. Existência de } \\
\text { documento de planejamento das ações, com previsão de repasse financeiro }\end{array}$ & $\begin{array}{l}\text { - IV Conferência } \\
\text { Estadual de Saúde } \\
\text { Mental - Intersetorial }\end{array}$ \\
\hline $\begin{array}{l}\text { Aspecto 15: Existência de espaços nos serviços de saúde para encontro } \\
\text { de usuários, familiares, técnicos e gestores das unidades, estimulando e } \\
\text { garantindo a participação de todos na formulação, no monitoramento e } \\
\text { na avaliação das ações dos serviços }\end{array}$ & $\begin{array}{l}\text { - IV Conferência } \\
\text { Estadual de Saúde } \\
\text { Mental - Intersetorial }\end{array}$ \\
\hline $\begin{array}{l}\text { Aspecto 16: Quantitativo de leitos de saúde mental em hospitais gerais e } \\
\text { em unidades pré-hospitalares para atendimento a crises, com recursos } \\
\text { humanos necessários e capacitados para o atendimento em saúde mental, } \\
\text { bem como supervisão clínico-institucional permanente de suas equipes }\end{array}$ & $\begin{array}{l}\text { - IV Conferência } \\
\text { Estadual de Saúde } \\
\text { Mental - Intersetorial }\end{array}$ \\
\hline $\begin{array}{l}\text { Aspecto 17: Garantia pelos ambulatórios e serviços substitutivos da rede } \\
\text { municipal de atendimento noturno nos dias da semana e turnos aos } \\
\text { sábados, com o objetivo de facilitar o acesso da população trabalhadora }\end{array}$ & $\begin{array}{l}\text { - IV Conferência } \\
\text { Estadual de Saúde } \\
\text { Mental - Intersetorial }\end{array}$ \\
\hline $\begin{array}{l}\text { Aspecto 18: Existência de veículos de passeio e ambulâncias nos serviços } \\
\text { de saúde (de saúde mental, atenção básica, ambulatórios e hospitais) } \\
\text { para realização de visitas domiciliares, atendimento de emergência } \\
\text { e agendamento para consultas e exames, caso haja dificuldade de } \\
\text { locomoção, de forma que cada unidade tenha seu veículo próprio a ser } \\
\text { utilizado de forma permanente para as ações de saúde mental }\end{array}$ & $\begin{array}{l}\text { - IV Conferência } \\
\text { Estadual de Saúde } \\
\text { Mental - Intersetorial }\end{array}$ \\
\hline $\begin{array}{l}\text { Aspecto 19: Existência de protocolo de atendimento e regulação do } \\
\text { Serviço de Atendimento Móvel de Urgência (SAMU), a fim de que os } \\
\text { serviços de saúde possam acioná-lo adequadamente }\end{array}$ & $\begin{array}{l}\text { - IV Conferência } \\
\text { Estadual de Saúde } \\
\text { Mental - Intersetorial }\end{array}$ \\
\hline $\begin{array}{l}\text { Aspecto 20: Existência de estratégia de atenção à crise na rede de } \\
\text { saúde municipal que garanta acesso em todos os níveis de atenção. } \\
\text { Existência de documentos que definam o fluxo de atendimento à crise e } \\
\text { de protocolos assistenciais e de regulação }\end{array}$ & $\begin{array}{l}\text { - IV Conferência } \\
\text { Estadual de Saúde } \\
\text { Mental - Intersetorial }\end{array}$ \\
\hline $\begin{array}{l}\text { Aspecto 21: Existência de supervisão clínico-institucional como estratégia política, } \\
\text { em consonância com a Reforma Psiquiátrica, para cada dispositivo da rede de } \\
\text { saúde mental, inclusive nas clínicas e nos hospitais contratados e conveniados }\end{array}$ & $\begin{array}{l}\text { - IV Conferência } \\
\text { Estadual de Saúde } \\
\text { Mental - Intersetorial }\end{array}$ \\
\hline $\begin{array}{l}\text { Aspecto 22: Existência de equipe multidisciplinar, interdisciplinar ou } \\
\text { transdisciplinar em todos os dispositivos de saúde mental }\end{array}$ & - Literatura \\
\hline \multicolumn{2}{|l|}{ Elemento 2: Oficinas terapêuticas } \\
\hline $\begin{array}{l}\text { Aspecto 23: Oferta, pelos dispositivos de saúde, de oficinas terapêuticas de } \\
\text { caráter expressivo, geradoras de renda e de alfabetização com vistas à promoção } \\
\text { do desenvolvimento de processos criativos respeitando as singularidades de } \\
\text { cada um. Existência de documento contendo a descrição das atividades, o } \\
\text { planejamento, o calendário de realização e a equipe responsável, bem como } \\
\text { relatório de monitoramento e avaliação das atividades desenvolvidas. Identificar } \\
\text { se há parcerias/convênios com outros setores (Assistência Social, secretarias de } \\
\text { Trabalho e de Cultura, dentre outras) para a realização dessas atividades }\end{array}$ & - Literatura \\
\hline
\end{tabular}




\begin{tabular}{|c|c|}
\hline Elementos da dimensão técnico assistencial & Referência \\
\hline \multicolumn{2}{|l|}{ Elemento 2: Oficinas terapêuticas } \\
\hline $\begin{array}{l}\text { Aspecto 24: Participação dos usuários dos serviços de saúde mental no } \\
\text { processo de planejamento das tarefas e atividades e dos horários, bem } \\
\text { como no monitoramento e avaliação delas }\end{array}$ & - Literatura \\
\hline \multicolumn{2}{|l|}{ Elemento 3: Projeto terapêutico } \\
\hline $\begin{array}{l}\text { Aspecto 25: Existência de projeto terapêutico institucional escrito } \\
\text { no âmbito dos componentes da RAPS, condizente com a Reforma } \\
\text { Psiquiátrica e produzido com a participação de todos os atores envolvidos } \\
\text { no processo de cuidado }\end{array}$ & - Literatura \\
\hline $\begin{array}{l}\text { Aspecto 26: Limites e possibilidades encontrados pelos profissionais } \\
\text { que atuam nos dispositivos de saúde mental para colocar em prática os } \\
\text { projetos terapêuticos institucionais e individuais }\end{array}$ & - Literatura \\
\hline $\begin{array}{l}\text { Aspecto 27: Existência de projeto terapêutico individual para todos } \\
\text { os indivíduos acompanhados pela rede de saúde mental, produzido } \\
\text { com a participação de todos os atores envolvidos no processo de } \\
\text { cuidado, inclusive os usuários e familiares, e condizente com a Reforma } \\
\text { Psiquiátrica, contribuindo para a reabilitação e a reinserção das pessoas } \\
\text { com transtorno mental na sociedade por meio da inclusão dos recursos } \\
\text { da comunidade e da participação de outros setores no projeto terapêutico }\end{array}$ & $\begin{array}{l}\text { - Portaria GM/MS } \\
\text { n. } 3.088 / 2011 \\
\text { - Literatura }\end{array}$ \\
\hline $\begin{array}{l}\text { Aspecto 28: Controle, pelos dispositivos de saúde, da frequência dos } \\
\text { usuários aos serviços, com busca ativa/visita domiciliar caso necessário }\end{array}$ & - Literatura \\
\hline \multicolumn{2}{|l|}{ Elemento 4: Alta hospitalar e acompanhamento terapêutico } \\
\hline $\begin{array}{l}\text { Aspecto 29: Existência de grupos de discussão multiprofissional, } \\
\text { interdisciplinar ou transdisciplinar para formular o projeto terapêutico } \\
\text { individualizado dos internos de hospitais psiquiátricos, dando início ao } \\
\text { processo de desinstitucionalização }\end{array}$ & $\begin{array}{l}\text {-ACP } \\
\text { - Literatura }\end{array}$ \\
\hline $\begin{array}{l}\text { Aspecto 30: Estratégias utilizadas em âmbito hospitalar em articulação } \\
\text { com os serviços substitutivos para preparação da alta hospitalar }\end{array}$ & - Literatura \\
\hline $\begin{array}{l}\text { Aspecto 31: Estratégias utilizadas pelas equipes para o preparado da } \\
\text { família para a alta hospitalar do indivíduo, bem como estratégias para } \\
\text { fortalecer o envolvimento dos familiares na continuidade do cuidado em } \\
\text { âmbito extra-hospitalar dos indivíduos }\end{array}$ & - Literatura \\
\hline $\begin{array}{l}\text { Aspecto 32: Notificação e acompanhamento dos casos de tentativa de } \\
\text { suicídio pelos serviços de saúde }\end{array}$ & $\begin{array}{l}\text { - IV Conferência } \\
\text { Estadual de Saúde } \\
\text { Mental - Intersetorial }\end{array}$ \\
\hline
\end{tabular}

Fonte: Elaboração própria.

\section{Considerações finais}

A presente pesquisa buscou analisar os principais aspectos do processo de desinstitucionalização a fim de contribuir para seu acompanhamento pelo Ministério Público Estadual. Para tanto, apoiou-se em Rotelli ${ }^{47}$ para a definição de desinstitu-

${ }^{47}$ ROTELLI, F.; LEONARDI, O.; MAURI, D. Desinstitucionalização uma outra via. São Paulo: Ed. HUCITEC, 1990. 
cionalização enquanto um processo social complexo e em Amarante ${ }^{48}$, adaptando as dimensões - técnico-assistencial, epistemológica, jurídico-política e sociocultural - da Reforma Psiquiátrica definidas pelo autor para o processo de desinstitucionalização a fim de classificar os aspectos pertinentes ao acompanhamento pelo MPE.

O esforço de categorizar os aspectos, por meio da sistematização dos elementos encontrados na revisão da literatura e análise documental, mostrou-se possível e pertinente na medida em que enfatiza apenas a preponderância de cada dimensão nos elementos identificados e selecionados, objetivação importante para o processo de acompanhamento da Política Nacional de Saúde Mental.

Destaca-se que a proposta de acompanhamento do processo de desinstitucionalização pelo Ministério Público Estadual é uma primeira aproximação e tentativa de oferecer um instrumento para a análise da questão. Não se pretendeu, portanto, esgotar os elementos pertinentes ao acompanhamento, tampouco avaliar a atuação do MPE. Nesse sentido, é inegável a importância da discussão desses resultados com os diversos atores envolvidos no processo de desinstitucionalização.

Também não houve a pretensão de apresentar um rol de indicadores de monitoramento e avaliação, visto que a criação de indicadores necessita de um processo metodológico particular, em especial do campo da avaliação. Porém, o resultado da pesquisa pode colaborar com estudos nesse sentido e estimular a avaliação e a identificação de indicadores de interesse do Ministério Público.

O presente trabalho apresentou aspectos importantes para o acompanhamento do processo de desinstitucionalização pelo Ministério Público Estadual e representa uma contribuição do campo da saúde ao Ministério Público na defesa do direito à saúde das pessoas com transtornos mentais. Espera-se que os resultados desta pesquisa sejam qualificados e complementados por outros estudos e com a utilização dos achados ora apresentados na prática do Ministério Público Estadual.

\section{Referências}

AMARANTE, Paulo. A (clínica) e a reforma psiquiátrica. In: AMARANTE, Paulo (Coord.). Arquivos de Saúde Mental e Atenção Psicossocial. Rio de Janeiro: Nau, 2003. p. 45-65.

AMARANTE, Paulo. O homem e a serpente: outras histórias para a loucura e a psiquiatria. Rio de Janeiro: Ed. Fiocruz, 1996.

AMARANTE, Paulo (Coord.). Loucos pela vida: a trajetória da reforma psiquiátrica no Brasil. 2. ed. rev. e ampl. Rio de Janeiro: Ed. Fiocruz, 2013.

${ }^{48}$ AMARANTE, Paulo. A (clínica) e a reforma psiquiátrica, cit., p. 45-65. 
ANAYA, Felisa Cançado. Problematização do conceito de serviços substitutivo em saúde mental: a contribuição do CERSAM de Belo Horizonte-MG. 2014. 155f. Dissertação (Mestrado em Saúde Pública) - Escola Nacional de Saúde Pública, Fundação Oswaldo Cruz, Rio de Janeiro, 2004.

ARANTES, Rogério Bastos. Direito e política: o Ministério Público e a defesa dos direitos coletivos. RBCS: revista brasileira de ciências sociais, v. 14, n. 39, p. 83-102, fev. 1999. Disponível em: http://www.scielo.br/pdf/rbcsoc/v14n39/1723.pdf. Acesso em; 11 abr. 2014.

ASENSI, Felipe Dutra. Indo além da Judicialização: o Ministério Público e a saúde no Brasil. Rio de Janeiro: Escola de Direitos do Rio de Janeiro da Fundação Getúlio Vargas, Centro de Justiça e Sociedade, 2010. 206p. Disponível em: https://bibliotecadigital.fgv.br/dspace/bitstream/ handle/10438/10313/Indo\%20al\%c3\%a9m\%20da\%20Judicializa\%c3\%a7\%c3\%a3o\%20-\%20 O\%20Minist\%c3\%a9rio\%20P\%c3\%bablico\%20e\%20a\%20sa\%c3\%bade\%20no\%20Brasil. pdf? sequence $=1$ \&isAllowed $=y$.

BARROS, Sônia; SALLES, Mariana. Gestão da atenção à saúde mental no Sistema Único de Saúde. Rev. esc. enferm. USP, São Paulo, v. 45, n. 2, p. 1780-1785, dez. 2011. http://www. scielo.br/pdf/reeusp/v45nspe2/25.pdf. https://doi.org/10.1590/S0080-62342011000800025.

BEZERRA, Cíntia Guedes; DIMENSTEIN, Magda. Acompanhamento terapêutico na proposta de alta-assistida implementada em hospital psiquiátrico: relato de uma experiência. Psicol. clin., Rio de Janeiro, v. 21, n. 1, p. 15-32, 2009. http://www.scielo.br/pdf/pc/v21n1/v21n1a02. pdf. https://doi.org/10.1590/S0103-56652009000100002.

BORSA, Juliane Callegaro; EIDELWEIN, Karen. Conhecendo a realidade da saúde mental no Rio Grande do Sul. Psico, PUC/RS, Porto Alegre, v. 36, n. 2, p. 159-165, 2005. https://www. researchgate.net/publication/260592314_Conhecendo_a_Realidade_da_Saude_Mental_no_ Rio_Grande_do_Sul.

DANTAS, Alexandre César. Serviços residenciais terapêuticos em saúde mental: potencialidades e limitações no município de Camaragibe/PE. Recife: [s.n.], 2010. 61p.

BIBLIOTECA VIRTUAL EM SAÚDE PÚBLICA. Descritores em Ciências da Saúde. Disponível em: http://decs.bvs.br/.

FERRO, Luís Felipe. Trabalho territorial em hospitais psiquiatricos: construindo no presente um futuro sem manicomios. Psicol. cienc. prof., Brasília-DF, v. 29, n. 4, p. 752-767, 2009. Disponível em: http://www.scielo.br/pdf/pcp/v29n4/v29n4a08.pdf. https://doi.org/10.1590/ S1414-98932009000400008.

FIGUEIREDO, Vanda Valle de; RODRIGUES, Maria Margarida Pereira. Atuação do psicólogo nos CAPS do Estado do Espírito Santo. Psicologia em Estudo, Maringá, v. 9, n. 2, ago. 2004. Disponível em: https://www.researchgate.net/publication/240768092_Atuacao_ do_psicologo_nos_CAPS_do_Estado_do_Espirito_Santo Acesso em: 08 jan. 2014. https:// doi.org/10.1590/S1413-73722004000200004.

GOFFMAN, Erving. Manicômios, prisões e conventos. São Paulo: Ed. Perspectiva, 1961. 
GUITTON, Anna Paula Aparecida de Lima. Trajetórias do processo de desinstitucionalização psiquiátrica no estado do Rio de Janeiro: uma análise a partir das estratégias políticas para o hospital psiquiátrico. 2010. 189 f. Dissertação (Mestrado em Saúde Pública) - Escola Nacional de Saúde Pública Sérgio Arouca, Rio de Janeiro, 2010. Disponível em: https://www.arca. fiocruz.br/handle/icict/23508.

GULJOR, Ana Paula Freitas. O fechamento do hospital psiquiátrico e o processo de desinstitucionalização no município de Paracambi: um estudo de caso. 2013. 356f. Tese (Doutorado em Saúde Pública) - Escola Nacional de Saúde Pública Sergio Arouca, Rio de Janeiro, 2013.

LIBERATO, Mariana Tavares Cavalcanti; DIMENSTEIN, Magda. Arte, loucura e cidade: a invenção de novos possíveis. Psicol. Soc., Belo Horizonte, v. 25, n. 2, p. 272-281, 2013. Disponível em: http://www.scielo.br/pdf/psoc/v25n2/04.pdf.

LIMA, Alyne Vieira. A gestão do processo de trabalho e a clínica: um estudo de caso no Hospital Colônia de Barreiros-PE. 2010. 74f. Dissertação (Mestrado em Saúde pública) Centro de Pesquisas Aggeu Magalhães, Fundação Oswaldo Cruz, Recife, 2010. Disponível em: https://www.arca.fiocruz.br/handle/icict/13688.

LUCENA, Marcela Adriana da Silva; BEZERRA, Adriana Falangola Benjamin. Reflexões sobre a gestão de processos de desinstitucionalização. Ciênc. saúde coletiva, Rio de Janeiro, v. 17, n. 9, p. 2447-2456, set. 2012. Disponível em: http://www.scielo.br/pdf/csc/v17n9/a25v17n9. pdf. https://doi.org/10.1590/S1413-81232012000900025.

MINISTÉRIO DA SAÚDE - MS. I Conferência Nacional de Saúde Mental. BrasíliaDF: Ministério da Saúde, 1987. Disponível em: http://bvsms.saude.gov.br/bvs/ publicacoes/0206cnsm_relat_final.pdf. Acesso em: 11 abr. 2014.

MINISTÉRIO DA SAÚDE - MS. II Conferência Nacional de Saúde Mental. Brasília-DF: Ministério da Saúde, 1994. Disponível em: http://bvsms.saude.gov.br/bvs/publicacoes/2conf_ mental.pdf. Acesso em: 11 abr. 2014.

MINISTÉRIO DA SAÚDE - MS. Reforma Psiquiátrica e política de Saúde Mental no Brasil. Brasília - DF: Ministério da Saúde, 2005.

MINISTÉRIO DA SAÚDE - MS. Saúde Mental no SUS: Os Centros de Atenção Psicossocial. Brasília-DF: Ministério da Saúde, 2004. Disponível em: http://www.ccs.saude.gov.br/ saude_mental/pdf/sm_sus.pdf.

MINISTÉRIO DA SAÚDE - MS. Secretaria de Atenção à Saúde/DAPE. Saúde mental em Dados 10, v. 7, n. 10, mar. 2012. Informativo Eletrônico. Brasília-DF. Disponível em http:// portal.saude.gov.br/portal/arquivos/pdf/mentaldados10.pdf. Acesso em: 16 jan. 2014.

MINISTÉRIO PÚBLICO DO ESTADO DE MINAS GERAIS (MPMG). MPMG Notícias Informativo da Procuradoria-Geral de Justiça de Minas Gerais, ano 13, n. 211, jul./ago. 2013. 
MINISTÉRIO PÚBLICO DO ESTADO DO RIO DE JANEIRO - MPERJ. Ministério Público e tutela à saúde mental: a proteção de pessoas portadoras de transtornos psiquiátricos e de usuários de álcool e drogas. 2. ed. Rio de Janeiro, ago. 2011. Disponível em http://msm. mp.rj.gov.br/wp-content/uploads/2013/01/cartilha_saude_mental_versao_final.pdf. Acesso em: 03 fev. 2014.

NASI, Cíntia; SCHNEIDER, Jacó Fernando. O Centro de Atenção Psicossocial no cotidiano dos seus usuários. Rev. esc. enferm., USP, São Paulo, v. 45, n. 5, p. 1157-1163, out. 2011. Disponível em: http://www.scielo.br/pdf/reeusp/v45n5/v45n5a18.pdf. Acesso em: 08 jan. 2014. https://doi.org/10.1590/S0080-62342011000500018.

PANDE, Mariana Nogueira Rangel; AMARANTE, Paulo Duarte de Carvalho. Desafios para os Centros de Atenção Psicossocial como serviços substitutivos: a nova cronicidade em questão. Ciênc. saúde coletiva, Rio de Janeiro, v. 16, n. 4, abr. 2011. Disponível em: http://www. scielo.br/pdf/reeusp/v45n5/v45n5a18.pdf. Acesso em: 08 jan. 2014. https://doi.org/10.1590/ S0080-62342011000500018.

PEPE, Vera Lúcia Edais. Internações e reinternações psiquiátricas no Estado do Rio de Janeiro. 2002. Tese (Doutorado) - Faculdade de Medicina da Universidade de São Paulo, São Paulo, 2002.

ROTELLI, F.; LEONARDI, O.; MAURI, D. Desinstitucionalização uma outra via. São Paulo: Ed. HUCITEC, 1990.

SADEK, Maria Teresa. A construção de um novo Ministério Público resolutivo. Palestra apresentada na Semana do Ministério Público de Minas Gerais, em 08/9/2008. Disponível em: https://aplicacao.mpmg.mp.br/xmlui/handle/123456789/135. Acesso em: 11 abr. 2014.

VIOLA, A.C.S. et al. Relatório final: Vigilância de Base Territorial Local na área de Influência do COMPERJ. Plano de Monitoramento Epidemiológico da área de Influência do Complexo Petroquímico do Rio de Janeiro. Escola Nacional de Saúde Pública. FIOCRUZ, 2013.

YASUI, Silvio. Rupturas e encontros: desafios da reforma psiquiátrica brasileira. 2009. Tese (Mestrado em Saúde Pública) - Escola Nacional de Saúde Pública Sérgio Arouca - FIOCRUZ, Rio de Janeiro. 2009. Disponível em: http://bases.bireme.br/cgi-bin/wxislind.exe/iah/ online/?IsisScript $=$ iah/iah.xis\&src=google\&base $=$ LILACS\&lang=p\&nextAction=lnk\&expr Search=490878\&indexSearch=ID. Acesso em: 11 abr. 2014. 
Ana Clara Viola - Mestrado em Saúde Pública pela Escola Nacional de Saúde Pública Sérgio Arouca (ENSP) da Fundação Oswaldo Cruz (Fiocruz); graduação em Saúde Pública pela Universidade Federal do Rio de Janeiro (UFRJ). Rio de Janeiro/RJ, Brasil. E-mail:soaresviola@gmail.com

Vera Lúcia Edais Pepe - Doutorado e Pós-doutorado no Departamento de Medicina Preventiva da Universidade de São Paulo (USP); mestrado em Saúde Coletiva pela Universidade do Estado do Rio de Janeiro (UERJ); graduação em Medicina pela UERJ. Departamento de Administração e Planejamento em Saúde, Escola Nacional de Saúde Pública Sérgio Arouca (ENSP) da Fundação Oswaldo Cruz (Fiocruz). Rio de Janeiro/RJ, Brasil.E-mail: verapepe@ensp.fiocruz.br

Miriam Ventura - Doutorado e mestrado em Saúde Pública pela Escola Nacional de Saúde Pública Sérgio Arouca (Ensp) - Fundação Oswaldo Cruz (Fiocruz); graduação em Direito pela Faculdades Integradas Augusto Motta. Professora Adjunta do Instituto de Estudos em Saúde Coletiva da Universidade Federal do Rio de Janeiro (IESC/UFRJ); coordenadora do Laboratório Interdisciplinar de Direitos Humanos e Saúde (LIDHS). Rio de Janeiro/RJ, Brasil. E-mail: miriam.ventura@iesc.ufrj.br 